\title{
Knowledge, Attitude and Practice Survey Tool for Intellectual Disability (KAP-ID)
}

\author{
Lakhan $\boldsymbol{R}^{1}$ \\ ${ }^{1}$ Dr.P.H. Epidemiology Candidate,Department of Epidemiology and Biostatistics,School of Health Sciences, \\ College of Public Services, Jackson State University, Jackson, MS, USA
}

\section{*Corresponding Author:}

Ram Lakhan

Dr.P.H. Epidemiology Candidate,

Department of Epidemiology and Biostatistics,

School of Health Sciences, College of Public Services, Jackson State University, Jackson, MS, USA

Email: ramlakhan15@gmail.com

\section{Citation}

Lakhan R. Knowledge, attitude and practice survey tool for intelectual disability (KAP-ID.) Nepal Journal of Medical Sciences 2014;3(1):22-25.

\begin{abstract}
Background: Community based rehabilitation approach is very popular in providing rehabilitation services to the people with intellectual disability in low and middle income countries. It is useful to assess level of knowledge, attitude and practices of parents and relatives of people with intellectual disabilities for strategic planning of the program.
\end{abstract}

Method: series of meetings, focus groups and in-depth interviews with the professionals employed in community based rehabilitation project and workers, and community members were conducted. Common questions around the issues related with intellectual disabilities were collected and discussed. These questions were refined with consultation, references with existing literature and field testing.

Result: We have developed and tested a Knowledge, Attitude and Practice survey tool for Intellectual Disability (KAP-ID) in a resource poor setting of a middle income country, India. This tool contains fifteen questions.

Conclusion: This brief survey tool is helpful in assessing knowledge, attitude and practices of parents, relatives and also of the community on intellectual disabilities. Information gained through the survey on KAPID found to be useful in designing the behavioral, awareness, educational, health promotional, and interventional program for the population with intellectual disabilities in rural poor settings.

Key words: intellectual disability, survey, tool, public health, communitybased rehabilitation, low and middle-income country

\section{Background:}

Intellectual disability (ID) is a public health problem. ${ }^{1-2}$ Therefore, it is better to apply public health, behavioral and health promotional strategies in intervention. Presently community based rehabilitation (CBR) approach is very popular in low and middle income countries. ${ }^{3-6}$ It applies several public health approaches in promoting health and prevention of diseases. CBR have four major components
1) medical, 2) educational, 3) economic and 4) social or community intervention. In medical intervention, person with ID receives appropriate medical services. Family members are educated and prepared to assist in intervention. Larger community including parents, relatives, villagers, government functionaries such as teachers, community workers and other members are educated under the section of social intervention. ${ }^{7}$ For any such program, it is very crucial to understand mind set of the parent's, relatives of the 
intellectual disabled people and community around them..$^{8-}$

9 CBR program are very flexible and can be customized as per the local needs. ${ }^{7,9-10}$ Following this philosophy, a survey can be planned to understand knowledge, practice and attitude of different groups in order to develop a culture sensitive and holistic interventional project plan. ${ }^{11-13}$ People with disabilities face higher rate of disparities in accessing health services. ${ }^{14}$ It is also very important to understand stigma that is most commonly associated with intellectual disability. ${ }^{15-17}$

Objective: design a knowledge attitude practice survey tool for intellectual disability for low and middle income country.

Methods: KAP-ID was developed in a very poor district of Madhya Pradesh state of India. A non-government organization Ashagram Trust (AGT) located in Barwani district had three community based rehabilitation / health projects. There was a need of understating parent's views, and practices on ID. Author of this research facilitated discussion in CBR core team. Focus groups and in-depth interviews were used with CBR team, CBRWs and community members. CBR team comprised various professionals from different fields such as psychiatrist, clinical psychologist, specialists in intellectual disabilities, orthotic-prosthetic engineers, social workers, physiotherapist, and other community workers. This team was interacting with ID population and their parents/relatives at regular basses. Common questions were collected after the discussion in this team. Then those questions were field tested by CBRWs and professionals of the CBR team. This was done with series of meetings at AGT, and in community, and findings of its use in another study are incorporated in this paper. ${ }^{11}$

Results: KAP-ID is a useful survey tool to use with parents and relatives of ID (Table -1). This was effectively used in another study. ${ }^{11}$ This tool measures 15 major issues those are commonly faced in LAMI countries when dealing with children with ID, more specifically in rural, impoverish and less educated communities. This tool can be implemented by any person who has basic ability of reading. Specific training is not required. It takes around 15 minutes to survey one participant. Survey tool should be administered on both parents separately to understand each parent. All questions have four answer choices, including one option as other. This tool is designed on the qualitative research methods. ${ }^{18-19}$ Tool can also be used with community members by skipping specific questions intend solely for parents.

Discussion: Administration of this survey tool in parent interviews itself develops some form of openness on the topic between service providers/interviewer and parents. This exercise helps in involving parents in interventional process. Involvement of parents in community programs for intellectual disabilities affects its outcome positively. ${ }^{20}$ KAP-ID found effective in measuring the knowledge, attitude and practices of parents towards their children with disabilities. Which greatly enhanced understanding of CBR team in dealing several management, service related issues with ID. Use of this tool assisted CBR team to modify and plan appropriate and cultural sensitive strategies of developing awareness and involving community in process of rehabilitation. ${ }^{11}$ Involvement of parents, and community in rehabilitation process helps in spreading awareness on ID issues. ${ }^{11,21-24}$

Table 1: Knowledge, Attitude and Practice Survey Tool for Intellectual Disability (KAP-ID)

\section{Knowledge, Attitude and Practice Survey Tool for Intellectual Disability (KAP-ID)}

Name of Child:

Age/D.O.B: Sex:

Level of Disability:

Information Provider:

Address:

Interviewer:

Date:

No

Questions

Is your child born with intellectual

1. disability due to your $\sin$ in previous life?

Selection Yes

No

No Idea

other

Yes

2.

Can faith healing make child with No intellectual disability all right? No Idea

Other

Yes

3. Can a person with intellectual No disability manage his / her own life? No Idea

$\begin{array}{cc} & \text { Othe } \\ \text { Should parent allow their ID child } & \text { Yes } \\ \text { No }\end{array}$

4. to play with their non-disabled peers?

No Idea

Other

Do you think a child with

Yes

No

5. intellectual disability benefits from school?

No Idea

Other

Yes

Do you think appropriate training No

6. improves condition of a child with No Idea intellectual disability?
Other 
Do you think a person with

7. intellectual disability can marry and enjoy her/his life?

Do you think a person with

8. intellectual disability can look after his/her property?

Do you think a child with

9. intellectual disability can learn new skills with stepwise training?

Do you think a child with

10. intellectual disability can be trained to speak? disability have disability certificate?

Do you involve your child with

12. intellectual disability in household activities?

What is the life span of a person

13. with intellectual disability in your opinion?

14. What are the causes of intellectual disability?

15. How do you manage behavior problems?
11. Is your child with intellectual

\section{Yes}

No

No Idea

Other

Yes

No

No Idea

Other

Yes

No

No Idea

Other

Yes

No

No Idea

Other

Yes

No

No Idea

Other

Yes

No

No Idea

Other

Normal

More

Less

No Idea

Other

Prenatal

Postnatal

Perinatal

All above

No Idea

Physically

punish

Leave/

ignore

Make

understand

Train

other

Any other observation made by interviewer while collecting information

Conclusion: KAP-ID was found easy to use, and useful in CBR programs for understanding mindset of people and planning interventional strategies. Tool also found feasible to implement, culturally sensitive, and useful for professionals in various rehabilitation settings.
Acknowledgement: The author sincerely thanks to Ashagram Trust Barwani and their financial partner Action Aid for allowing him to conduct this research. He also thanks to all CBR workers, CBR professionals, and all parents of people with intellectual disabilities for their participation in the research.

Conflict of Interest: declared none

\section{References:}

1. Lakhan R. Social, Environmental and Biological Determinants of Cerebral Palsy in Children with Intellectual Disabilities (ID) in India. Nepal Journal of Epidemiology 2013; 3: 262-68. http://dx.doi.org/10.3126/nje.v3i3.9187

2. Lakhan R. Intelligence quotient is associated with epilepsy in children with intellectual disability in India. Journal of Neurosciences in Rural Practice 2013; 4: 408-12.

http://dx.doi.org/10.4103/0976-3147.120241

3. Lakhan R. Inclusion of Children with Intellectual and Multiple Disabilities: A Community-Based Rehabilitation Approach, India. Journal of Special Education and Rehabilitation 2013: 14: 79-97. http://dx.doi.org/10.2478/v10215-011-0035-1

4. Kumar SG, Roy G, Kar SS. Disability and rehabilitation services in India: Issues and challenges. Journal of Family Medicine and Primary Care 2012; 1: 69-73. http://dx.doi.org/10.4103/2249-4863.94458

5. Cameron DL, Nixon S, Parnes $\mathrm{P}$, et al. Children with disabilities in low-income countries. Paediatrics \& child health 2005; 10: 269-72.

6. Alam KJ, Bari N, Khan MA. Community based rehabilitation practices and alleviation of poverty of people with disabilities in Bangladesh. In Workshop on Community-Based Rehabilitation (CBR) and Poverty Alleviation of Persons with Disabilities. Bangkok. 2005 Available at, (http://www.dpiap.org/national/pdf/ community based_rehabilitation.pdf)

7. Carter EW, Trainor AA, Ditchman N, et al. Communitybased summer work experiences of adolescents with high-incidence disabilities. The Journal of Special Education 2011; 45: 89-103. http://dx.doi.org/10.1177/0022466909353204 
8. Ahmad I, Qadir S, Yasir M, et al. Knowledge, Attitude and Practice Related to Occupational Health and Safety among textile mills workers in Dera Ismail Khan. Gomal Journal of Medical Sciences 2012; 10: 222-26.

9. Robertson J, Emerson E, Hatton C, et al. Efficacy of Community-Based Rehabilitation for Children with or at Significant Risk of Intellectual Disabilities in Low- and Middle-Income Countries: A Review. Journal of Applied Research in Intellectual Disabilities 2012; 25:143-54.

http://dx.doi.org/10.1111/j.1468-3148.2011.00638.x

10. Morrissey C, Taylor J, Bennett C. Evaluation of a therapeutic community intervention for men with intellectual disability and personality disorder. Journal of Learning Disabilities and Offending Behavior 2012; 3: 52-60.

http://dx.doi.org/10.1108/20420921211236933

11. Lakhan R, Sharma M. A study of knowledge, attitudes and practices (KAP) survey of families toward their children with intellectual disability in Barwani, India. Asia Pacific Disability Rehabilitation Journal 2010; 20: 101-17.

12. Simkhada PP, Shyangdan D, Teijlingen VER, et al. Women's knowledge of and attitude towards disability in rural Nepal. Disability and Rehabilitation 2013; 35: 606-13.

http://dx.doi.org/10.3109/09638288.2012.702847

13. Kaur G. Public awareness, attitudes and beliefs about intellectual disability: a Sikh perspective. Doctoral dissertation, UCL, University College London 2011; 1 Available at, (http://discovery.ucl.ac.uk/1338985/1/ Gurpreet $\% 20$ Kaur\%20DClinPsy $\% 20$ Vol\%201.pdf)

14. Ouellette-Kuntz H. Understanding health disparities and inequities faced by individuals with intellectual disabilities. Journal of Applied Research in Intellectual Disabilities 2005; 18: 113-21.

http://dx.doi.org/10.1111/j.1468-3148.2005.00240.x

15. Scior K, Addai-Davis J, Kenyon M, et al. Stigma, public awareness about intellectual disability and attitudes to inclusion among different ethnic groups. Journal of Intellectual Disability Research 2012; 57: 1014-26.

16. Sheridan J, Scior K. Attitudes towards people with intellectual disabilities: A comparison of young people from British South Asian and White British backgrounds. Research in developmental disabilities 2013; 34: 1240-47.

http://dx.doi.org/10.1016/j.ridd.2012.12.017

17. Antony PJ. How Do Social, Cultural and Educational Attitudes towards Disability Affect Families of Children with Disabilities and There by Affect the Opportunities and Daily Experiences of People with Disabilities in Kerala-India? Doctoral dissertation, Washington State University 2009; Available at, (http://www. dissertations.wsu.edu/Dissertations/Summer2009/p antony_090109.pdf)

18. Sofaer S. Qualitative research methods. International Journal for Quality in Health Care 2002; 14: 329-36. http://dx.doi.org/10.1093/intqhc/14.4.329

19. Ritchie J. The applications of qualitative methods to social research. Qualitative research practice: A guide for social science students and researchers 2003; 24-46.

20. Einfeld SL, Stancliffe RJ, Gray KM, et al. Interventions provided by parents for children with intellectual disabilities in low and middle income countries. Journal of Applied Research in Intellectual Disabilities 2012; 25: 135-142.

http://dx.doi.org/10.1111/j.1468-3148.2011.00678.x

21. Coles S, Scior K. Public attitudes towards people with intellectual disabilities: a qualitative comparison of white British \& South Asian people. Journal of Applied Research in Intellectual Disabilities 2012; 25: 177-88. http://dx.doi.org/10.1111/j.1468-3148.2011.00655.x

22. Reichow B, Servili C, Yasamy MT et al. NonSpecialist Psychosocial Interventions for Children and Adolescents with Intellectual Disability or LowerFunctioning Autism Spectrum Disorders: A Systematic Review. PLoS medicine 2013; 10:1-27, e1001572.

23. Green S, \& Baker B. Parents' emotion expression as a predictor of child's social competence: children with or without intellectual disability. Journal of Intellectual Disability Research 2011; 55: 324-338. http://dx.doi.org/10.1111/j.1365-2788.2010.01363.x

24. Estes A, Vismara L, Mercado C et al. The impact of parent-delivered intervention on parents of very young children with autism. Journal of autism and developmental disorders 2014; 44; 353-365. http:// dx.doi.org/10.1007/s10803-013-1874-z 